\title{
Evaluación científica a las teorías del origen de la vida e inclusión del modelo bíblico como una explicación alternativa
}

\author{
Andrés Álvarez García ${ }^{1}$, Idiany Gamboa Hernández ${ }^{2}$, Jhony Alberto García ${ }^{3}$, \\ Raúl Cedeño Pincay ${ }^{4}$, Richard Bolaños Cubides ${ }^{5}$ \\ ${ }^{12345}$ Corporación Universitaria Adventista
}

Recibido: 02 de noviembre de 2016

Aceptado: 10 de enero 2017

\section{Resumen}

El objetivo de esta investigación consiste en evaluar de forma sucinta las principales teorías del origen de la vida y proponer razones puntuales para considerar el relato bíblico como una alternativa confiable respecto a los orígenes. La investigación tiene un enfoque cualitativo de carácter descriptivo. Para la recolección de datos se emplea la técnica de fichaje bibliográfico, que permite organizar el estado del arte de las teorías del origen de la vida y del relato del Génesis. Diversos autores y líneas investigativas enlistan características que se relacionan con la aparición de la vida, pero no existe una definición clara de vida en la comunidad científica. Las teorías del mundo del RNA, la panspermia, y las membranas prebiológicas abordan el origen de la vida desde un enfoque abiogénico, gradualista y evolutivo. Por otro lado, en la protología del Antiguo Cercano Oriente se encuentra el relato del Génesis bíblico como una narrativa histórica, secuencial y amítica, que tiene características diferenciadoras respecto a las cosmogonías sincrónicas del Enuma Elish, Eridu Genesis y Atrahasis. En conclusión, las teorías actuales del origen de la vida comportan limitaciones significativas en su abordaje, lo cual dilucida la posibilidad de considerar el texto Bíblico de la creación como una teoría alternativa al origen de la vida.

Palabras clave: Vida, Abiogénesis, Protología, teorías científicas, origen, Cosmogonía.

\begin{abstract}
The purpose of this research is to succinctly evaluate the main theories of the origin of life and to propose specific reasons to consider the biblical story as a reliable alternative to the origins. The research has a qualitative approach of descriptive character. For the data colletion is used the technique of bibliographic transfer, which allows to organize the state of the art of theories of the origin of life and the Genesis account. Several authors and research lines to list characteristics that

${ }^{1}$ Correspondencia al autor

E-mail: aljuarismi20@gmail.com
\end{abstract}


are related to the appearance of life, but there is no clear definition of life in the scientific community. Theories of the world of RNA, panspermia, and prebiological membranes address the origin of life from an abiogenic, gradualist and evolutionary approach. On the other hand, in the protology of the Near East lies the account of Biblical Genesis as a historical, sequential and amictic narrative, which has differentiating characteristics with respect to the synchronic cosmogonies of Enuma Elish, Eridu Genesis and Atrahasis. In conclusion, the current theories of the origin of life carry significant limitations in their approach, which dissuades the possibility of considering the biblical text of creation as an alternative theory to the origin of life.

Keywords: Life, abiogenesis, protology, scientific theories, origin, cosmogony.

\section{Introducción}

Todas las teorías de los orígenes confrontan el desafío de estudiar hechos del pasado que no pueden ser observados, tales como el origen del universo, la tierra y la vida. Las alternativas que se han postulado para dar una explicación a dichos cuestionamientos son básicamente dos: las teorías dadas por las ciencias históricas (arqueología, paleontología) y los relatos de escritos fundacionales (Biblia, odisea, etc.)

El estudio de los orígenes implica ahondar en conceptos complejos, en particular el concepto de vida, que es el objeto de estudio del presente texto. Pero "¿A qué se refieren los científicos cuando se mencionan la vida en frases como "evolución de la vida" o "la vida en otros planetas” o “cuándo comenzó la vida”? En realidad, no hay una definición simple de qué es la vida, esta existe en abstracto. Más aún, no hay una manera sencilla y única de trazar la línea entre lo vivo y lo no vivo" (Curtis, 2008, p.13).

En torno al origen de la vida la ciencia ha generado múltiples teorías basadas principalmente en la abiogénesis, que han partido desde el caldo biológico de Oparin hasta los protobiontes de Fox. Por otro lado, el relato fundacional de la creación en el libro de Génesis narra la acción de un Dios bondadoso que genera ambientes adecuados para el surgimiento de la vida en una semana literal.

Las anteriores alternativas comportan inquietudes de envergadura: ¿Se puede obtener vida a partir de materia inorgánica de forma espontánea? ¿Es posible que una fuente extraterrestre haya traído la vida a la tierra? ¿El RNA puede ser considerado como un precursor de las primeras 
células? ¿Es el relato del génesis una historia mítica o un registro fidedigno acerca del origen de la vida? ¿La vida surgió por medio de un proceso gradual o de una acción inmediata? ¿Qué implicaciones teleológicas tiene adoptar una de las posturas?

\section{Conceptualización de la vida}

Los primeros acercamientos al concepto de vida se desarrollaron a través de la filosofía. Tales de Mileto veía en el agua el origen de todas las cosas, él pensó que este componente de la materia podría dar origen a la vida, incluyendo a la humanidad (Schopf, 2002, p.14). Por otro lado, Berdau (2005) afirma que "Aristóteles solía pensar que las cosas vivas se distinguían de los objetos inanimados por la habilidad de organizarse a sí mismos y mantener su auto-organización contra perturbaciones internas y externas" (p.1). Finalmente, Couprie (2003) recopila información que valida que "Anaximandro consideraba que los seres vivos emergen de algún tipo de mezcla primitiva activada por el calor del sol” (p.34).

Así, la evolución del concepto de vida involucra aportes intuitivos y simples que se obtuvieron por medio de la razón o instrumentos sencillos de experimentación. Algunos pensaron que la vida podría corresponder con una propiedad de la materia como la masa, pero al pesar un organismo vivo antes y después de su muerte, no se logra encontrar una pérdida de masa debido a la ausencia de vida, lo cual generó el indicio que la vida era un concepto abstracto. Por otra parte, Oparin consideraba la vida como un peldaño en la historia de la materia, y dicho peldaño podría ser alcanzado por medio de mecanismos que implicaran materia abiótica (Oparin, 2000, p.20).

Actualmente, según Van Loon (2005) “muchos biólogos correlacionan la presencia de DNA o al menos RNA como un criterio sustancial para la vida" (p. 335). No obstante, la vida involucra muchos procesos y características adicionales como la presencia de membrana selectiva, metabolismo, reproducción y mutación (Lazcano, 2009, p. 8). Es por ello que la vida desde un punto de vista biológico no se puede definir en sí misma, pero se caracteriza por medio de los aspectos observables que presenta en el ambiente.

Científicos de la Universidad de Rice (2003) han postulado características para identificar la vida, como: “orden, sensibilidad, respuesta ante los estímulos, reproducción, adaptación, crecimiento, desarrollo, regulación, homeostasis, y procesamiento de energía" (p.33). Por otro lado, 
la NASA adopta una definición de vida más general, como "un sistema que es capaz de realizar metabolismo y propagación de información" (Shaw, 2006, p.5).

La célula es la unidad estructural y funcional de los seres vivientes, ella es considerada la precursora de la biósfera de la tierra. La vida a nivel celular comporta cuatro características esenciales que permiten distinguirla: "La existencia de una membrana que separe la célula del ambiente circundante y le permite mantener su identidad bioquímica, la presencia de enzimas, proteínas complejas esenciales para las reacciones químicas de las que depende la vida, la capacidad de replicarse, generación tras generación y la posibilidad de evolucionar a partir de la producción de descendencia con variación” (Curtis, 2008, p.15).

También otras áreas de la ciencia han realizado recientes estudios y han llegado a proponer un grupo de atributos universales para la vida, tales como: explosión del desequilibrio termodinámico del entorno para mantener su propio estado de desequilibrio, interactuación entre moléculas que promuevan la reactividad química, presencia de un disolvente líquido que apoye estas reacciones e implementación de un mecanismo capaz de evolución darwiniana (Hays, 2015, p.144). Estos atributos muestran como algunos autores consideran que la vida está ligada al concepto de evolución, pero el término llega a hacer ambiguo mientras no se clarifique si hace referencia a la adaptación, la selección natural o a la totalidad de procesos evolutivos.

Por otro lado, la ciencia categoriza ciertos sistemas como "prebiológicos" (previos a la vida), incluso aplica conceptos evolutivos a dichos sistemas para explicar su desarrollo. Tales sistemas vendrían a evolucionar debido a una serie de transacciones conducentes a una sucesión de estados cada vez más complejos y organizados. El desarrollo de dichos estados requirió de “evolución química", un concepto que pretende aplicar los mecanismos selectivos de la evolución biológica a las estructuras químicas (Berenguer, 1996, p.67).

Zairoswki y Friedrich (2008) "El problema general con el estudio de los orígenes de la vida es que incluso la forma de vida más simple conocida es mucho más compleja que cualquiera de los componentes no vivos que podrían haber contribuido a ella" (p. 6). Es por esta complejidad que entraña el concepto que se consideran aspectos complementarios provenientes de la metafísica, para desarrollar una comprensión holística del término vida. 
La vida según Campbell (2004) desde una perspectiva antropológica es también conciencia y vitalidad (p. 118). La existencia del ser humano llega a ser la cúspide de la vida, debido al desarrollo del lenguaje y la conciencia como atributos de su interactuar complejo con el entorno. Por otra parte, la teología considera al ser humano más allá del biologismo social e incursiona en el concepto de alma, como atributo intrínseco de las funciones exteriores de la vida antropológica. Siendo el alma un sentido de vida en la teología veterotestamentaria, pero alejado del concepto de alma que la filosofía griega atribuye (Ernst y Westermann, 1997, p.752).

\section{Teorías científicas del origen de la vida}

Inicialmente se estudió el origen de la vida a través del paradigma de la generación espontánea, este concepto propuesto por Oparin (1953) declaraba que "los seres vivos surgían de forma natural a partir de la materia inanimada" (p. 30). Debido a la carencia de métodos, instrumentos y cientificidad en el abordaje del tema de los orígenes esta concepción perduró a través de las edades, atribuyendo el surgimiento del reino animal a impresiones y mitos populares.

Por otro lado, la abiogénesis según Persaud (2007) plantea que "la vida se originó a través de materia inorgánica por medio de reacciones químicas desarrolladas bajo condiciones ideales" (p. 119). Así, la abiogénesis es el concepto actualizado de la generación espontánea que ha tratado de encontrar explicaciones científicas para el surgimiento de la vida.

De este modo, las teorías del origen de la vida que surgieron, tomaron el concepto de abiogénesis, pero rechazaron la generación espontánea debido a su carácter mítico y poco experimental. Gargaud, Amils y Cleaves (2011) aseguran que “Tomas Huxley usó el término abiogénesis en un importante texto publicado en 1970. Él estrictamente hizo la diferencia entre la generación espontánea, -que no aceptó- y la posibilidad de la evolución de la materia inerte a la vida, sin ninguna influencia de vida preliminar" (p. 1853).

Oparin y Haldane plantearon conceptos inaugurales para explicar el origen de la vida a través de la abiogénesis. La teoría de Oparín-Haldane, en esencia según Ahad (2011) "se basa en las condiciones de la tierra primitiva, en la capacidad de interacción de los compuestos químicos que da lugar a compuestos más complejos, y en la evolución gradual de la materia inorgánica, hasta formarse las primeras células" (p. 6). Haldane denominó "sopa primitiva" al conjunto de 
compuestos químicos contenidos en los mares primigenios (Cambell, 2011, p.508).

Las condiciones primitivas de la tierra para Oparin se basaban en una atmósfera muy diferente a la actual. El "aire" primitivo estaría compuesto mayormente de hidrógeno, metano, amoniaco y vapor de agua, lo cual generaría un ambiente sin oxígeno; este planteamiento de una atmósfera reductora solucionaría la dificultad existente del surgimiento de las reacciones químicas primordiales. Seguidamente, bajo la influencia de la luz solar, y del calor de las erupciones volcánicas, esos gases reaccionarían y darían compuestos orgánicos (Silver, 1998).

No obstante, MacKenzie (2004) afirma que la luz ultravioleta proveniente del sol podría generar dosis letales en la superficie de la tierra primitiva por su carencia de capa de ozono, donde la vida de acuerdo al proceso teórico de Oparin no podría haberse logrado (p. 326). Por otro lado, a pesar de las limitaciones del modelo, Lazcano (1966) asevera que "Oparin transformó el estudio del origen de la vida desde una perspectiva puramente especulativa del problema en un programa de investigación viable" (p. 220).

En el siglo XX avanzó la teoría de abiogénesis utilizando los recursos científicos que se habían desarrollado para la época. Futuyma (2005) afirma que "Miller y Urey realizaron síntesis de moléculas orgánicas simples utilizando recipientes de vidrio cerrado, fuentes de energía eléctrica y sustancias gaseosas con la composición de la atmósfera primitiva (hidrógeno, metano, amoníaco y vapor de agua)" (p. 93). Dicho modelo experimental comporta dificultades de tipo intencional, estructural y químico, ya que no se puede reproducir con certeza las condiciones primitivas del planeta tierra en un laboratorio.

Ellos obtuvieron diversos aminoácidos los cuales se encuentran en las proteínas, y azúcares como la glucosa, ribosa y desoxirribosa que son esenciales para la vida. No obstante, dicha síntesis bioquímica sobrelleva problemáticas de isomería óptica debido a los carbonos quirales que tienen estas moléculas. Por ejemplo, se formó L-glucosa y D-glucosa siendo biológicamente activa solamente la dextrógira (D). Por lo tanto, todas las moléculas no son precursoras directas de la vida, incluso se generan mezclas racémicas que inactivan ópticamente el resultado.

La abiogénesis actualmente plantea un orden teórico de eventos, el cual varía según el autor consultado. En particular, Barton (2007) plantea los siguientes siete pasos: 
la generación de molécula orgánicas simples a partir de inorgánicas, evolución química que produce moléculas más complejas y redes metabólicas primitivas, el origen de la autorreplicación y la creación de genotipos, compartimentación y creación de células, el enlace genotipo y fenotipo, el origen del código genético, y la toma de control de sistemas de replicación temprano por intervención del DNA (p. 92).

La anterior secuencia de eventos para lograr el surgimiento de la vida puede ser explicada por medio de diversas teorías y experimentaciones. En el presente texto se discutirán principalmente tres: la hipótesis del mundo del RNA, la panspermia y las membranas primitivas. Dichas teorías no son necesariamente excluyentes, ya que algunos teóricos complementan o combinan los argumentos de estas.

\section{La hipótesis del mundo del RNA}

Freeman (2001) plantea la siguiente pregunta: “¿Cuál molécula, DNA o RNA, apareció primero en el mundo prebiótico? Muchos científicos han sugerido que el RNA fue la primera molécula informativa que evolucionó para dar lugar al DNA, proteínas y finalmente la célula” (p. 474). De acuerdo a esta teoría, Solomon (2005) considera que la Tierra prebiótica dio lugar a moléculas de RNA autorreplicantes que funcionaban como enzimas y sustratos (p. 338). Dicha propuesta surgió a finales de 1960 de manera independiente por Carl R. Woese, Francis Crick y Leslie Orgel, y posteriormente en 1986 el premio nobel de la universidad de Harvard Walter Gilbert lo nombra El Mundo del RNA" (Szostak y Bartel, 2001, 388).

La hipótesis del mundo RNA de la evolución temprana de la vida disfruta de una incrementada aceptación y cierto apoyo experimental. La declaración más simple de la teoría del mundo RNA según Pouplana (2011) es que "la historia evolutiva incluye por lo menos un organismo que depende sobre las moléculas de RNA ambos como el recipiente primario para la información genética y como el principio fijado de catálisis para las funciones celulares” (p. 46).

Para Schopf (2010): "la razón para elegir el RNA como precursor de la información genética es debido a sus características catalíticas replicantes que se han encontrado en las ribozimas"(p.143). Estas reacciones catalíticas pudieron darse en arcillas, rocas superficiales o chimeneas hidrotermales. Los estudios de evolución in vitro han mostrado que el RNA puede catalizar una variedad de importantes reacciones biológicas. "El surgimiento del DNA se daría por la incorporación de dos hélices de RNA, una vez sintetizado el DNA, ya el RNA tomaría el rol que 
cumple actualmente" (Solomon, 2005, p. 389).

La hipótesis del mundo del RNA según Martin y Müller (2015) teóricamente lleva la siguiente secuencia: "Precursores químicos, síntesis de nucleótidos, activación de nucleótidos, polimerización, surgimiento de ribozimas. Síntesis de DNA, y obtención de proteínas” (p. 251). Los anteriores pasos varían dependiendo el autor que se consulte, sin embargo, la secuencia dada tiene amplia aceptación en los círculos académicos. A continuación, se discutirán estas etapas con la finalidad de realizar una evaluación al modelo.

El primer ítem a evaluar es la síntesis de nucleótidos y su posible ocurrencia en la tierra primitiva. Martin y Müller (2015) definen que "un nucleótido es la fusión de tres componentes discretos: un grupo fosfato, un azúcar de ribosa y una base nitrogenada” (p. 251), de estos tres componentes el que conlleva mayor importancia y dificultad de síntesis son las bases nitrogenadas (Guanina, citosina, Uracilo y Adenina). Juan Oró (1961) sintetizó “adenina mediante una reacción con amoniaco y cianuro de hidrógeno la cual tuvo un rendimiento de 0,5\%" (p. 1193-1194), luego otros científicos sintetizaron citosina y uracilo.

No obstante, la síntesis de nucleótidos tiene múltiples dificultades. Algunos de estos problemas para Rauchfuss (2008) surgen en "el enlace de los átomos 3-N de las pirimidinas y los átomos 9-N de las purinas con el átomo 1-C de la ribosa, llevado a cabo sin un control enzimático y bajo las condiciones de la tierra primitiva” (p. 144). También existe la limitación que las síntesis se han logrado en proporciones muy pequeñas, que podrían ser exterminadas por el medio ambiente circundante. De este modo, según Gáspar (2010) “el análisis de los resultados experimentales sobre la síntesis de las bases nitrogenadas deja claro que algunos de ellos fueron "forzados" mediante condiciones muy drásticas" (p. 165). Por ejemplo, una síntesis de guanina requiere concentraciones de cianuro tan altas como $2,2 \mathrm{M}$.

Seguidamente, el proceso de activación hace referencia según Higgs y Lehman (2014) a "los nucleótidos que están preparados con un enlace de alta energía para facilitar su condensación con otros nucleótidos" (p.2). Dicho proceso sobrelleva limitantes experimentales, que para Rizzotti (1995) radican principalmente en "la ausencia de nucleótidos activados de obtención natural, y nuevamente la falta de condiciones prebióticas plausibles que garanticen la supervivencia del producto" (p.215). Así, se puede apreciar que el mundo del pre-RNA tiene el desafío de lograr 
resultados sintéticos que se puedan acercar a los postulados que plantea la teoría y que a su vez logren corroborar las predicciones computacionales (Mulkidjanian, Cherepano y Galperin, 2003, p.12)

La síntesis de RNA es poco conocida, pero se postulan diversas alternativas para su ocurrencia. Según Zaikowski y Friedrich (2008): "se han realizado estudios sobre las montmorillonitas (silicatos del tipo arcilloso) con el objetivo de conocer su mecanismo de catálisis y su papel potencial en la síntesis prebiótica de RNA” (p. 302). Otra alternativa es la hipótesis de la fuente hidrotermal que intenta dar un ambiente propicio para la vida en las profundidades del mar. Por otro lado, Joyce (1996) considera que "la obtención del RNA con capacidad autoreplicante sería la clave para darle validez a la teoría" (p. 966). Ya que las ribozimas no sólo catalizarían los ácidos nucleicos sino los precursores mismos del RNA, de este modo, los hallazgos de diferentes RNAs con capacidad catalítica son asociados directamente con la teoría del mundo del RNA (Gilbert y Souza, 1999, p. 14).

Estudios que han investigado la replicación del RNA en el laboratorio usan tres enfoques diferentes. El primero es dirigido por molde de polimerización no enzimática, en el que una cadena de RNA promueve la formación de su cadena complementaria, sin la presencia de una ribozima. El segundo es la polimerización de RNA por una ribozima de RNA polimerasa general (o replicasa) que cataliza la copia de una cadena molde para hacer una secuencia complementaria de la plantilla, y el tercero es el desarrollo de las redes de moléculas que catalizan la formación de otras secuencias específicas en la red de manera que la red en su conjunto es mutuamente autocatalítica (Higgs y Lehman, 2014, p.3).

Sin embargo, para Dworkin, Lazcano y Miller (2003) hay una limitante en los estudios de ribozimas es que los primeros catalizadores eran mucho más lentos y menos selectivos que las enzimas modernas. Por esta razón algunos bioquímicos como Johnston y Unrau (2001) creen que "la comprensión actual de la química prebiótica argumenta contra la aparición de cantidades significativas de moléculas de RNA, ni siquiera la décima parte de su longitud” (p. 22).

Otra restricción de la teoría es el papel primitivo que desempeña el RNA que es diferente al que actualmente realiza en la célula, debido a esto se denomina el viejo y el nuevo RNA. Así, Szweykowska (2014) para "la existencia del mundo del RNA requeriría un número mucho mayor 
de vías y catalizadores que se asemejen al metabolismo moderno" (p. 35). Aunque otros teóricos consideran que los mundos del viejo y nuevo RNA están conectados metabólicamente, debido a las funciones que el RNA realiza en la actualidad con el DNA y las proteínas.

Finalmente, el desafío principal de la hipótesis del mundo del RNA radica en la homoquiralidad de las moléculas, tanto de los ácidos nucleicos como las proteínas. La salida que se ha encontrado para esto según Flugel (2011) es que "los aminoácidos quirales se formaron a través de la importación de los meteoritos del exterior con la posterior transferencia de quiralidad a otras moléculas" (p. 20). Otra explicación surge de la evolución in vitro por medio de la evaporación de nucleósidos y la hidrólisis de los mismos.

Algunas preguntas que deja pendientes este modelo son: ¿Cómo se podría haber logrado la regioespecificidad y la estereoespecificidad necesaria? ¿Cómo se podrían haber logrado los primeros polímeros de RNA en ausencia de ribozimas? ¿Cuál fue la fuente de energía que dio origen al mundo del RNA? (Martin y Müller, 2015, p. 263)

\section{Teoría de la panspermia}

La teoría de la panspermia también llamada exobiogénesis comporta la posibilidad que la vida llegara a la tierra desde el exterior (el espacio). La panspermia según la forma de inclusión de la vida en la tierra se divide en tres clases: la litopanspermia que hace al transporte de la vida por medio de meteoritos, la radiopanspermia que atribuye la entrada de vida a la presión de radiación estelar, y finalmente la panspermia dirigida que adjudica la inclusión de la vida a seres extraterrestres existentes (Giuli, 2010, p.45).

La panspermia para Hoyle y Wickraa (2000): "no aborda la cuestión del origen último de la vida, sólo su transferencia una vez que se ha originado" (p. 15). Así, este aspecto viene a generar controversia respecto a si la panspermia es una teoría del origen de la vida o simplemente una explicación posterior de la aparición terráquea de la misma. Sin embargo, en el presente documento se abordará como una teoría del origen de la vida debido a su amplia difusión y aprobación científica.

Según Woolfson (2015) el modelo evolutivo los primeros organismos celulares "surgieron hace aproximadamente 3,6 millones de años, dando lugar a las bacterias y arqueas, que no tienen 
núcleo y otros orgánulos subcelulares" (p. 520). En particular, para Baracaldo (2015) "las cianobacterias tienen un papel fundamental en la transformación geoquímica de la tierra primitiva y para evidenciarlo hay múltiples registros de cambios ambientales generados en el periodo proterozoico" (p. 5).

Los indicadores que se utilizan para saber cuándo se ha encontrado evidencia de vida pasada incluyen: primeramente, fósiles creados en la roca que preservan las formas físicas de los organismos o comunidades de microorganismos individuales. Además, los componentes moleculares de la vida, es decir, compuestos orgánicos específicos, o un conjunto de moléculas secas, y finalmente los subproductos de los procesos biológicos, en particular los productos de desecho de las reacciones para obtener la vida utilizando energía (Hays, 2015, p. 145).

Por otra parte, las observaciones del cometa Halley utilizando espectrometría de masas de impacto a bordo de la nave espacial Vega 1 proporcionó pruebas que el polvo del cometa se compone de un núcleo condrítico con un manto orgánico compuesto principalmente por sustancias altamente insaturadas. Thomas y Chyba (1997) “muchas de estas son moléculas orgánicas cíclicas y acíclicas secos como benceno y tolueno, y pequeñas también incluyen pirrol, imidazol, piridinas, adenina y pirimidinas" (p. 35).

De este modo, Peña (2004\}) asegura que "en exámenes de microondas emitidas y absorbidas por moléculas características se han identificado diversos compuestos orgánicos en el espacio, entre ellos: hidrocarburos, aminas, alcoholes y nitrilos" (p.13). También algunos compuestos meteoríticos tienen contrapartes idénticas en la biósfera y apoyan la propuesta referente a que su envío exógeno a la Tierra primitiva podría haber favorecido la evolución molecular. Particularmente Pizzarello (2009) considera que“es la asimetría L exclusiva como su rica y casi exclusiva composición soluble en agua también descubierta aparentemente en otros tipos de meteoritos" (p. 253).

Nuevamente, ingresa el problema del origen de la homoquiralidad en los compuestos químicos relacionados con la vida en la tierra. Para esto no hay una explicación gradual lógica de aparición, Shaw (2006) considera que sólo se sabe que "hay una pequeña diferencia de energía entre los isómeros ópticos, y que la homoquiralidad requerirá la ampliación biológica de un enantiómero sobre el otro" (p. 8). En consecuencia, la panspermia intenta encontrar en los 
meteoritos pruebas de la inmersión homoquiral a la tierra como explicación de su difusión exclusiva actual.

Por otro lado, Stojanovic (2008) define que "la astrobiología estudia el origen, evolución, distribución y futuro de la vida en el universo" (p. 5). Uno de los objetivos importantes de la astrobiología es descubrir la vida o signos de vida en planetas fuera de la tierra, para lo cual ha investigado a seres vivos extremófilos. Estos son organismos que crecen en ambientes extremos de temperatura, salinidad, $\mathrm{pH}$, presión o sequedad; lo cual les atribuye la posibilidad de sobrevivir al ambiente cósmico.

El descubrimiento de las bacterias y arqueas que ocupan los entornos más duros de la Tierra sigue proporcionando un apoyo indirecto a la panspermia. Transferencias viables de vida microbiana de un hábitat cósmico a otro requiere la resistencia de altas y bajas temperaturas, así como la exposición a bajos flujos de radiación ionizante entregados en escalas de tiempo astronómicas, típicamente millones de años. (Wickraa, 2009, p. 43).

En particular, Marte es un planeta en el que la radiación UV intensa es absorbida en la superficie e interior de su corteza, lo cual genera grandes fluctuaciones de temperatura. Para lo cual un organismo termófilo podría sobrevivir a dichos cambios. Así, se ha demostrado que "las esporas desnudas bacillus subtilis no podrían sobrevivir al viaje interplanetario, pero con algún tipo de escudo, por el contrario, tendría posibilidades de conseguirlo, un escudo podría ser hielo, la propia roca o el carbón" (Lepock y Wesson, 1994, p. 15). Sin embargo, Anders (1989) afirma que "cuando los meteoros y cometas chocan contra la tierra, la fricción de la atmósfera y la colisión con el suelo generan una gran cantidad de calor" (p. 256). Por esta razón, aunque los posibles precursores de la vida hayan tenido un escudo protector en el espacio, no garantiza la supervivencia a la entrada atmosférica.

Por otro lado, según Yamaguchi (2012) "los meteoritos se clasifican principalmente en dos grupos de rocas: condritas y acondritas” (p. 131). Los meteoritos acondritos contienen rocas ígneas, hierro y morfología pedregosa, donde el grado de fusión es variable. Los meteoritos condritos están compuestos por las rocas más primitivas del sistema solar, en particular es de interés de la exobiología las rocas condritas carbonaceas, ya que contienen un residuo orgánico rico en hidrocarburos aromáticos. Ellos poseen desde 0.35 a $4.8 \%$ de carbono versus $0.1 \%$ de los 
meteoritos ordinarios (Peña, 2004, p. 22).

Un concepto relevante en los estudios de rocas en el espacio es el kerógeno. Esto para Zairowski y Friedrich (2008) "refiere a materia orgánica terrestre macromolecular insoluble, que se define operacionalmente como el residuo orgánico que queda después de la desmineralización ácida de una roca" (p. 250). Cabe señalar que el kerógeno meteorítico es significativamente diferente de kerógeno terrestre.

A continuación, se analizarán los siguientes cuerpos espaciales de interés: meteorito de Murchinson, meteorito ALH84001 y Titán (luna de Saturno).

El meteorito de Murchinson recibe su nombre de la localidad Murchinson, Victoria en Australia, los fragmentos de meteorito cayeron en el pueblo en 1969. Para Zairowski y Friedrich (2008) “el meteorito de Murchinson tiene un rico inventario orgánico, incluyendo ácidos carboxílicos, aminoácidos, ácidos sulfónicos dicarboximidas y ácidos dicarboxílicos, hidrocarburos alifáticos y aromáticos y otras clases de moléculas orgánicas” (p. 250).

Un hallazgo de importancia en el meteorito de Murchinon según Pizzarello (2009) es "la asimetría molecular de algunos aminoácidos que daría evidencia que las síntesis abióticas aparentemente al azar que produjeron materia orgánica con un grado de selección quiral” (p. 255). El desarrollo de homogeneidad quiral podría haber sido un proceso evolutivo que implicó la catálisis y que la asimetría quiral única de aminoácidos de meteoritos que podría haber transferido su asimetría a otras moléculas esenciales para la vida en la tierra.

Estos estudios estereoquímicos de aminoácidos en Murchinson se han llevado a cabo durante 20 años, encontrando según Engel y Macko (2001) “una cantidad mayoritaria del enantiómero L" (p. 35). Aunque no se ha encontrado una explicación concreta para este hecho, pero se considera como un reto futuro que podría dar explicación a la vida actual en el mundo. Asimismo, dichos aminoácidos para Wong y Lazcano (2009) podrían comportar características similares a las encontradas en las proteínas del planeta tierra (p. 48).

Por otro lado, algunos estudios realizados por Martins (20089 han demostrado que las purinas y pirimidinas encontradas en el meteorito de Murchinson son de origen extraterrestre (p. 131). También Engel y Macko (2001) han considerado que el "enriquecimiento de C-13 y N-15 de 
los aminoácidos Murchison demuestra aún más sus orígenes extraterrestres” (p. 43). Ya que en la tierra la abundancia química principal es de los isótopos C-12 y N-14, lo cual mostraría que esta cantidad isotópica es atípica de la corteza terrestre.

Otro factor estudiado en este meteorito por Carrapico y Rodrigues (2005) es la presencia de compuestos "anfifílicos aislados que tiene la capacidad de auto-ensamblaje en membranas vesiculares, esto podría indicar una posible ruta sobre la manera primitiva de formación y evolución de estos sistemas" (p. 23). Los sistemas anfifílicos tienen gran importancia biológica principalmente en la síntesis de proteínas, lo cual los hace teóricamente estructuras precursoras.

El meteorito ALH84001 de origen marciano es un meteorito que contiene rocas acondritas encontrado en la Antártida. Este hallazgo es de importancia en la exobiología ya que Shaw (2006) sugiere que "dentro de la roca aparecen estructuras que se parecen a organismos fósiles" (p. 9). Este meteorito fue expulsado de la superficie de Marte probablemente por una colisión, la evidencia para este origen marciano se basa principalmente en la comparación de gases absorbidos dentro del meteorito y la composición del ambiente marciano determinado en las misiones Viking.

Otros estudios realizados de tipo isotópico son consistentes con un entorno neutral para la oxidación de la superficie de los carbonatos. Estas líneas de evidencia según Kirschvink y Weiss (2001) sugieren que en comparación al planeta tierra, "marte primitivo podría haber tenido un mayor suministro de energía biológicamente utilizable para dar origen a la vida” (p.8).

Estos hallazgos se ven eclipsados debido a que Shaw (2006) reporta que recientes descubrimientos han "mostrado contaminación humana ya sea durante el aterrizaje, recolección o análisis de los meteoritos" (p. 172). En particular, en el ALH84001 se ha encontrado que el agua de fusión penetró las estructuras del hielo contaminando la corteza del cuerpo espacial con los componentes terráqueos.

Otro cuerpo espacial de importancia para el origen de la vida es el satélite de Saturno llamada Titán. Este es considerado según Horneck y Rettberg como “uno de los cuerpos más interesantes del sistema solar en relación con la astrobiología” (p. 225). Ya que Raulin (2007) considera que Titán "guarda diversas similitudes con la tierra, en particular, ambos tienen una atmósfera densa compuesta principalmente de nitrógeno molecular y un ambiente muy rico de 
compuestos orgánicos” (p. 379). La misión Cassini-Huygens a través de su desarrollo, ha inducido a un gran aumento en el número de programas de investigación dedicados a la química orgánica de Titán.

No obstante, algunas dificultades que sobrelleva el estudio de la exobiología entrañan importantes limitantes al modelo. Un problema particular es la búsqueda de evidencia inequívoca de las reliquias prebiológicas en el registro geológico. También la inminente propensión a la contaminación por parte de los meteoritos arribados a la corteza terrestre y el conjunto de compuestos orgánicos presentes en las nubes interestelares, que dirige constantemente la búsqueda de los orígenes de la Tierra a lugares cada vez más distantes del universo ( Wickram, 2009, p. 43).

\section{Vestigios de las células: membranas pre-biológicas}

En experimentos de laboratorio se han sintetizado diversos tipos de membranas, las principales son: liposomas, coacervados y protobiontes. La importancia en el estudio de las membranas es generar una aproximación a la célula por medio de la inclusión de material genético (previamente sintetizado) a estos sistemas.

Los liposomas según Peña (2004) pueden “contener moléculas orgánicas, tener capacidad semipermeable, presentar fenómenos osmóticos y exhibir fisión” (p. 28). Por otro lado, Campbell (2011) define que "los protobiontes son agregados de moléculas rodeados por una membrana y exhiben reproducción simple de su sistema" (p. 509). Estos dos tipos de membrana pueden mantener un ambiente químico interno diferente a sus alrededores. La coacervación para Bohidar (2008) se define generalmente como "la formación espontánea de una fase líquida densa de una solución macromolecular de mala afinidad disolvente" p. 21). La formación de tales fluidos de macromoléculas es conocida en mezclas polielectroliticas con partículas coloidales, que conduce a condensación de fases de materia blanda.

Por otro lado, Maxwell (1994) relata que "Sídney Fox en 1972 propuso otra alternativa de síntesis abiótica por medio de su teoría térmica, ésta aborda la problemática considerando el calor como una fuente esencial de energía en la tierra primitiva" (p. 12). Fox se convirtió en un fuerte defensor de la idea que las proteínas provenientes de ambientes en temperaturas extremas (lava) tomaron forma de pequeñas esferas con capacidad motriz que comportaban algunas características 
básicas de la vida incluida la reproducción simple y el metabolismo, manteniendo un ambiente químico distinto a sus alrededores (Campbell, 2011, 509).

Él observó que a altas temperaturas los aminoácidos tienden a encadenarse aleatoriamente constituyendo los denominados proteinoides, dotados de propiedades catalíticas respecto a las reacciones químicas ordinarias. Berenguer (1996) afirma que "los proteinoides se agregan espontáneamente entre 130 y $180^{\circ} \mathrm{C}$ para formar micro esferas (1-2 micrómetros de diámetro) que desarrollan una demarcación externa análoga a una membrana biológica corriente, a pesar de que no haya lípidos presentes" (p.48). Esto llevó a formular la hipótesis que tal vez las células evolucionaron partiendo de estructuras parecidas a las microesferas protonoides.

Los protobiontes exhiben varios atributos funcionales y estructurales semejantes a las células vivas. Estos mantienen un ambiente químico interno que es diferente al ambiente externo y algunos de ellos manifiestan indicios metabólicos. En particular, las microesferas son un tipo de protobionte formado por la adición de agua a los polipéptidos formado abióticamente. Algunas microesferas son excitables: producen un potencial eléctrico a través de sus superficies, que recuerda a los gradientes electroquímicos en las células (Solomon, 2005, p. 338).

Algunos científicos han sintetizado protenoides por medio de ensambles de polipéptidos producidos abióticamente, pero los protenoides no son propiamente organismos vivos. La teoría de Fox requiere de explicaciones adicionales respecto a la evolución gradual de los protenoides hasta llegar a células procariotas.

Además, las características que estos sistemas exhiben son considerablemente distintas a la estructura altamente selectiva de la bicapa fosfolípida de las membranas celulares actuales. Así, la transición de la macromolécula a la célula es un salto de dimensiones fantásticas, que se sitúa fuera del ámbito de las hipótesis verificables. Los hechos disponibles no proporcionan una base suficiente para postular que las células aparecieran en este planeta.

En resumen, el origen de la vida a partir de la ciencia posee una limitante que radica en la variedad de teorías existentes. Por esta causa requiere de la unificación de todas las teorías propuestas para lograr la focalización de la investigación y así llegar a mejores productos experimentales. Por ello, se puede afirmar que científicamente no se ha llegado a un modelo satisfactorio que logre responder los principales cuestionamientos respecto al origen de la vida. 


\section{El relato de la creación judeo-cristiano como una explicación alternativa al origen de la vida}

\section{Comparación de relatos acerca de la creación de la vida en el Antiguo Cercano Oriente}

En la historiografía del mundo antiguo quedan registros de cosmogonías pertenecientes a civilizaciones antiquísimas que expusieron sus percepciones sobre la creación y el origen de la vida. Así, en el presente trabajo investigativo se analizan algunos de estos relatos, tales como: Enuma Elish, Atrahasis y Eridu Genesis. Estos son textos representativos de la cultura y percepción del antiguo cercano oriente que realizan un abordaje de los orígenes de la humanidad.

Las cosmogonías babilónicas se caracterizaron por el politeísmo y la mitología de carácter altamente fantástico. También se les adjudican a los dioses características moralmente despectivas y caprichosas en el desempeño de sus actividades creadoras. Por otro lado, el Génesis bíblico hace parte de los relatos mesopotámicos que narra el origen de la naturaleza y la humanidad, pero ha sido datado en una fecha posterior.

Según Horowitz (1998) el relato del Enuma Elish está comprimido en siete tablillas, en las primeras seis "narran el proceso de evolución del universo desde los tiempos más remotos a través de la construcción de Babilonia. En la séptima tablilla los dioses otorgan cincuenta nombres a Marduk" (p. 118).

En el principio de acuerdo al Enuma Elish, existían dos dioses que fueron dando origen a otros dioses. Frederic (1990) presenta que "el origen de las cosas es compartido por varios seres divinos, y que el mismo Marduk, presentado como la deidad patrona fue traído a la existencia misma por otra deidad” (p. 30). King (2005) considera al Enuma Elish como un reto para la filología por su paralelismo con otras cosmogonías establecidas en el Cercano Oriente. "tal relato consta de la creación del Universo, de la formación de todo por medio de batallas entre los dioses, y posteriormente la supervivencia de los humanos" (p. 15).

Este relato mesopotámico comporta diferencias claras respecto al registro Mosaico. Refiriéndose al relato del Génesis Bergant (2000) expone que "aunque hay similitudes entre este relato y el relato de la creación de Babilonia en el Enuma Elish; el autor sacerdotal ha reinterpretado y reescrito el mito antiguo para reflejar la teología distintiva de Israel” (p. 35). En contraste al 
Enuma Elish, la creación no resulta desde el Conflicto. No hay guerra entre los dioses, no hay nada que se oponga a Dios, Él crea el mundo solamente por el poder de su palabra.

Groseclose (2015) define que el Enuma Elish "es un relato que contiene un lenguaje monárquico, mientras que el Génesis se basa en la soberanía y justicia de Dios” (p. 385). El Génesis incluye la creación de todos los aspectos de la naturaleza, mientras que el Enuma Elish ignora la creación de estos elementos. Del mismo modo, en el Génesis se puede observar que todo es producido por medio de la palabra de Dios, más en Enuma Elish la creación es generada por medio de la magia. Dios según el relato del Génesis hizo al hombre a su imagen y semejanza, mas Enuma Elish propone el inicio del hombre de parte de Marduk y Ea por medio de la sangre de los dioses (Groseclose, 2015, p. 385).

El Enuma Elish es por excelencia politeísta. Este narra el conflicto político que hubo entre los dioses, previo a la creación del hombre, siendo este un actuar por parte de Marduk. Dicho relato según Gowan (1988) tiene intenciones claramente políticas ya que su uso en "el festival babilónico ayudó a responder a una necesidad humana básica por la seguridad que el tiempo y el mundo podría ser renovado" (p. 49)

Otro de los textos del mundo antiguo que se ocupan del tema del origen y sus implicancias es El Atrahasis. Se tiene constancia de la existencia de este relato protológico sinóptico al relato del Génesis, pero con diferencia de contenido, forma literaria, y finalidad. La cosmogonía en Atrahasis en similitud con los otros relatos se basa en una deidad creadora. Con base a esto Dundes (1988), "la épica Atrahasis comienza con una descripción del mundo como existente antes que el hombre fuese creado. En este tiempo, el Universo fue dividido entre grandes dioses, con An tomando los cielos, Enlil la tierra y Enki el gran abismo" (p. 61). Siete dioses se establecieron a ellos mismos como una clase gobernante, aunque el resto de los dioses proveyeron una fuerza obrera.

La majestuosidad y egocentrismo es habitual en tal relato so pretexto de que hay individuos inmersos allí que propugnan pleitesía ante las deidades. Albert Clay (2003) es consistente con la afirmación anterior cuando manifiesta que "El Atrahasis constituye una de las primeras formas de mitología, donde nos encontramos con los dioses y diosas en las posiciones habituales de poder y autoridad" (p. 2). Aunque la autoridad judeo-cristiana es leal a 
la posición de que el relato de Atrahasis y el Génesis Mosaico son diferentes en cuanto a finalidad se refiere, es indiscutible pasar por alto que existe algunas similitudes entre estos dos relatos.

Respecto a lo mencionado anteriormente, Walton (2004) lo corrobora y amplía diciendo: "Hay vínculos indiscutibles entre el Atrahasis y el relato Mosaico de la creación. Ambos comienzan con la creación. En Atrahasis se resume el trabajo de los dioses, mientras que en Génesis también se propicia el trabajo de Dios” (p. 41). Después ambos relatan la creación del hombre, y ambos registran un crecimiento numérico de la humanidad. Las semejanzas encontradas allí son habituales en relatos antiguos porque ambas regiones estaban regidas por culturas similares, y tendían a creer en deidades creadoras de todo. Al proponer un paralelismo, es posible percibir tal ideología tanto en el Génesis Mosaico como en la teología protológica de Atrahasis.

Aunque el enfoque general de Atrahasis es el Diluvio, deja ver en su epílogo alguna forma poética sobre la creación de todo. Los críticos presentan al Génesis y Atrahasis como paralelos tanto en contenido como en finalidad. Sin embargo, tal afirmación conlleva problemas en cuanto a dimensiones históricas, culturales y espaciales. Históricas porque hay desigualdad en datación; culturales porque las creencias divinas son completamente discordantes; y espaciales en el sentido en que son diversos territorios, y es sabido que la geografía condiciona las creencias.

Entre el Génesis y Atrahasis hay dos características distintivas, y que a su vez protagonizan una coyuntura antagónica: (1) la violencia del relato de atrahasis, y la pacificada creación en el Génesis, (2) el relato de Atrahasis es politeísta, mientras que el Génesis el monoteísta. Tal percepción localiza al génesis en un espacio de control, por cuanto una deidad específica ubica, controla y ordena el orbe (Staats, 2012, p. 32).

Otro de los relatos en cuestión es el Eridu Génesis. De los mitos mesopotámicos, es el que más se aproxima al Génesis mosaico, pues hay un contenido similar en estos. Jacobsen describe al Eridu Génesis diciendo:

Este mito, en el cual el comienzo está perdido, describió la creación del hombre por cuatro grandes dioses: An, Enlil, Ninitur y Enki. Después que Nintur ha decidido activar al hombre 
desde su zona de acampada nomádica primitiva hasta la ciudad. El periodo de la vida comenzó cuando los animales florecieron sobre la tierra y el reinado cayó desde el cielo. Las ciudades más tempranas fueron construidas, fueron nombradas, tuvieron cupos medidos, emblemas de sistema económico redistribucional, asignado a ellos, y fueron divididos entre los dioses (Jacobsen, p. 76).

El Eridu Génesis fue escrito sobre tabillas en escritura cuneiforme, método habitual en Mesopotamia. Hay ciertas partes ausentes de este relato, que a su vez pueden ser reconstruidas desde otros textos.

La inverosimilitud de tales compilaciones es dejada de lado cuando se examinan los demás documentos mesopotámicos que contienen vestigios de relatos protológicos. Hay algunos aspectos en los que el Génesis de Moisés parece conectar con Eridu Génesis, tales como: (1) la creación del hombre; (2) creación de un reino o monarquía; (3) la construcción de las primeras ciudades; (4) los reyes quienes gobernaron antes del Gran Diluvio; (5) La inigualable decisión del dios Enlil de querer destruir a la humanidad pecadora; (6) se relata allí un gran diluvio. Desde tal catálogo de características, se puede divisar ciertos paralelos entre ambos relatos. Tal panorama es observado por Arnold (2009) cuando manifiesta que "Los fragmentos del Eridu Génesis Sumerio han sido preservados en varias versiones desde aproximadamente 1600 antes de la era cristiana. Pone en secuencia la creación de la humanidad, la institución del reinado, las primeras ciudades, y el gran diluvio en una forma reminiscente al Génesis” (p. 39).

A pesar de que existan muchas semejanzas entre el Génesis Mosaico y el relato mesopotámico Eridu Génesis, existen diferencias insalvables. La primera sugerencia es que en el Génesis Mosaico se presente una deidad con un orden, y sin necesidad de utilizar su poder para hacer violencia; en Eridu Génesis, las deidades entran en conflicto. La segunda sugerencia es que del relato del Génesis se han encontrado registros escritos; en Eridu Génesis no se ha encontrado algo con fiabilidad puesto que tales tablillas de Eridu Génesis están perdidas, en la sección de la creación. La protología del Eridu Génesis es conflictiva y no es posible divisar un orden congruente.

\section{Modelo bíblico de la creación de la vida en el Génesis}

El World Biblical Commentary hace una descripción pertinente del Génesis. Wenham (1987) afirma que "este es un recuento de la antigua tradición oriental sobre cómo fue creado el 
mundo, pero con un enfoque hacia la naturaleza del verdadero Dios como un solo ser, omnipotente, omnisciente y bueno" (p. 10); en contraposición a las falibles, caprichosa y débiles deidades que propugnan el resto de relatos del mundo antiguo. El génesis explica y narra que todo lo creado fue hecho únicamente por el evidente poder de Dios; porque Él no necesitó instrumentos para crearlo, Él pudo trabajar sin herramientas; porque Él no necesitaba nada para empezar a trabajar. No hubo un proceso intermediario entre la palabra dicha por Dios y el resultado en cada aspecto de la creación; Dios simplemente habló, y fue hecho (Schweitzer, p. 1).

Por otro lado, surge la necesidad de descifrar si el Génesis bíblico es un mito como los relatos mesopotámicos sincrónicos, lo cual conlleva a conceptualizar y analizar este estilo literario. Según Bultmann (1961) "la mitología es el uso de imágenes para expresar lo sobrenatural en términos naturales y lo divino en términos de vidas humanas, realidades superiores, en términos inteligibles" (p. 10). El pensamiento Mítico-religioso busca las causas de los fenómenos más allá de la naturaleza, es un intento de explicación a los interrogantes planteados por la humanidad.

Hamilton sugiere tres formas como el Antiguo testamento maneja el material mítico. En primer lugar, un mito puede separarse de su contexto original para expresar una nueva realidad (Is. 11:6-9) o como figura extendida de expresión (Is. 14:12-21). Los mitos deben ser historizados como saga o leyenda (Exo. 4:24-26). En tercer lugar, los fragmentos míticos se aíslan de manera significativa de su marco teológico (Hamilton, 1990, p. 58).

Aunque dentro de algunos círculos teológicos se ha constatado que es probable que la forma de elaboración del Génesis sea un relato mítico, al parecer no se ha evidenciado mucho soporte arqueológico respecto al Génesis. Lo anterior no masifica la tesis de que no se encuentre evidencia arqueológica, sino que todavía está en desarrollo de búsqueda. Sin embargo, se han hallado algunos "rastros" de tinte paleográfico en distintas estructuras allende a los lugares descritos en los relatos del Génesis que conducen a una fiabilidad del relato mosaico como un texto amítico.

La plausibilidad de encontrar regiones espaciales que describe el relato protológico del Génesis es alto. Se constata en la actualidad la verosimilitud del relato Mosaico en conexión con los descubrimientos arqueológicos. Sweeny (2008) soporta lo precedente y avizorando el panorama del Diluvio, arguyendo que "El evento importante más temprano de la Biblia es el 
Diluvio de Noé, el cual es dicho haber cubierto la tierra y destruido la mayoría de humanos y vida animal. Arqueólogos en muchas partes del mundo hallaron abundante evidencia de la destrucción cataclísmica, consistente con la acción de las aguas del Diluvio” (p. 7). Las regionalizaciones de los límites de las ciudades descritas en el Génesis también han sido soportadas gracias a la evidencia arqueológica.

En este respecto, Hushbeck (2004) comenta:

Ahora que los hallazgos de los arqueólogos han incrementado significativamente, la narrativa de los patriarcas puede ser comparada con estos hallazgos. Entre los muchos puntos que han sido confirmados por arqueólogos son las ciudades que están descritas en Génesis como ciudades inhabitadas durante el tiempo de los patriarcas, tales como Betel y Hebrón, estuvieron inhabitadas durante este tiempo. Nombres encontrados en Génesis, tales como Abrahám, Terá, Nahor y Labán, han sido también encontrados en los escritos de este periodo (p. 66).

Se ha constatado en muchas formas la consistencia arqueológica del Génesis.

El génesis bíblico utiliza una estructura gramatical que desmitologiza su relato, esto se evidencia principalmente con el uso de los términos "lumbrera mayor" y "lumbrera menor" (Gen. 1:16) que contrastan con la adoración a los dioses luna y sol en el Antiguo Cercano Oriente. Pratte (2000) considera que "el único enfoque adecuado para el Génesis es visualizarlo como una historia de inspiración divina. No es leyenda o mito, ni es simbólica” (p. 189). A excepción de los símbolos ocasionales que son empleados de forma explícita y que se interpretan en otras secciones del canon bíblico.

A causa de las anteriores evidencias Von Rad (1982) se sugiere que "el lenguaje del Génesis es amítico" (p. 56). Debido a ello Hamilton (1990) afirma que "los léxicos, comentarios y datos arqueológicos atestiguan que el relato mosaico es de naturaleza histórica” (p. 59). Finalmente, es menester aclarar que el libro del génesis no es un libro de naturaleza científica y sus primeros once capítulos no se escriben con el propósito de explicar detalladamente cómo el mundo llegó a ser, pues el pensamiento hebreo es sustancialmente distinto al encontrado en la filosofía pre-socrática (Rice, 1994, p. 13).

\section{Breve análisis gramatical de la creación de la vida en el Génesis}

El libro del génesis fue escrito originalmente en el idioma hebreo. Debido a ello se 
analizarán algunos términos de importancia para la comprensión e interpretación del relato, en particular los vocablos o secciones que se consideren relacionadas con el origen de la vida.

Inicialmente, se realiza la hermenéutica de إלְדז (Toledot) y Ayð (yom) debido a su importancia semántica y literaria en la protología Mosaica. El significado de "toledot" וְּ̣" corresponde a "generaciones "o "registro de genealogías" y Ауð (yom) refiere a tiempo o día.

La hermenéutica de toledot realiza importantes a portes a la comprensión de la aparente contraposición del relato de Génesis capítulo uno y capítulo dos. De forma general el término se introduce en un sentido de genealogías, origen organizado de algo, o puede significar "Dar a luz". En particular, para Von Rad (1982) "el vocablo toledot se puede traducir en Gen 2:4a en el sentido muy amplio de "historia de los orígenes" (p. 83). Es por ello que al referirse a Toledot, Berkhof (1988) menciona:

El sobrescrito 'eleh toledot, que se encuentra 10 veces en Génesis, nunca se refiere al principio u origen de las cosas sino siempre a sus generaciones, es decir, a su historia posterior. Esa expresión data de un tiempo cuando la historia consistía en la descripción de las generaciones. El segundo capítulo de Génesis principia con la descripción de la historia del hombre, arregla su material de acuerdo con este propósito y únicamente repite parte de lo que ya se había dicho en el capítulo primero, sin ninguna consideración del orden cronológico, según se necesita para el propósito del autor (p. 87).

Con lo anterior podemos argüir que Génesis 2 no menciona una nueva creación, sino que utiliza parte del primer capítulo para exponer el origen y la genealogía del ser humano.

Este modo de concebir la creación lleva consigo consecuencias teológicas trascendentales. La creación es una acción histórica de Yahvéh, una obra dentro del tiempo. Ella abre realmente el libro de la historia. Cierto, por ser la primera obra de Yahvéh, se encuentra al principio absoluto de la historia; pero no está sola, otras le seguirán. Von Rad (1982) afirma que "el documento sacerdotal acentúa de modo particular su situación en el tiempo, cuando la incluye en el esquema de las toledot (generaciones), su gran armazón genealógico (Gen 2, 4a); más aún, la misma creación es un proceso temporal, medido en 6 días" (p. 139). Ahora bien, "si la historia de la creación se halla en el tiempo, entonces deja de ser para siempre un mito, una revelación atemporal que tiene lugar en el movimiento cíclico de la naturaleza” (Von Rad, 1982, p. 139). 
Por otro lado, hay una gran discusión en torno al carácter temporal del creacionismo bíblico, ya que algunos designan eones de tiempo al proceso, mientras otros literalmente los siete días que se relatan. Debido a ello existen corrientes teológicas que intentan armonizar el Génesis con el tiempo geológico dado por la paleontología estratigráfica. Erickson (2008) clasifica las teorías concorditas que se han desarrollado como: "Teoría reconstruccionista, teoría del diluvio, teoría de la edad aparente, teoría concordista y teoría literalista” (p. 402). Así, en el desarrollo de la postura creacionista se hará una breve argumentación gramatical explicando por qué no es adecuado adoptar el tiempo propuesto por estas teorías.

En el primer capítulo del Génesis se emplea el término "yom" traducido específicamente como día. Jenni y Westerman (1997) “Al igual que en la mayoría de los idiomas, este significado básico se aplica para día (de 24 horas), "en el sentido de la unidad astronómica o de calendario (en la posibilidad de formar este concepto con la expresión de" noche "en los otros idiomas)" (p. 528). Sin embargo, yom es empleado en otras secciones de la Biblia como época, tiempo o fecha. El carácter polisémico de yom conlleva dificultades para su hermenéutica en el texto mosaico.

Pero el uso de Yom es muy frecuente en el registro veterotestamentario, dando dos connotaciones, por ejemplo: "Cuando la palabra yôm ("día”) es empleada junto con un numeral lo que se repite 150 veces en el Antiguo Testamento- se refiere invariablemente a un día de 24 horas. Esta regla es persistente en el Antiguo Testamento, la única excepción en los números de uno a mil se encuentra en un texto escatológico en Zacarías 14:7. La expresión hebrea yôm echad empleada en este texto se traduce de varias maneras: "Será único ese día" (Nácar-Colunga); "Y será un día señalado" (Versión Moderna); y varias otras formas según la versión. Se reconoce que es un texto difícil en hebreo, y por lo tanto no cabe hacer comparaciones con el uso de Génesis 1" (Hasel, 2015, p. 12)

Un criterio semántico y sintáctico para abordar esta problemática hermenéutica es expuesto por Gentry (2016) quien dice:

Las relaciones sintagmáticas de yom en Génesis 1 se han considerado y se ha demostrado que, cuando se utiliza con un número, el patrón es siempre un período de tiempo normal. Si la noche se combina con yom que siempre denota día de 24 horas. Si yom se utiliza, ya sea con, mañana o tarde ellos también se refieren al día literal. Cuando mañana y la tarde se usan juntos, con yom siempre significa un día solar. 
Por otro lado, Hasel (2015) realizó un estudio de léxicos y comentarios que le permitieron hallar que "hay eruditos liberales y no liberales que afirman que la palabra "día" en Génesis 1 tiene que ser exclusivamente entendida en su sentido literal” (p. 12). Así, en el análisis gramatical del vocablo hebreo en cuestión, reposa un argumento sólido para afirmar que los días expuestos en el Génesis, no son largas épocas o lapsos de tiempo desconocidos; por el contrario los días del relato hebreo denotan claramente un constructo de 24 horas literales.

Para la comprensión armónica de la vida y su origen en el relato mosaico, es menester examinar con minucia el día tres del mencionado relato; día en el que la vida hace su aparición y se introduce en el escenario creacionista.

Génesis 1:3 relata el primer día de la creación: "Y dijo Dios: Sea la luz; y fue la luz". La creación de la luz propició el ambiente de energía con lo cual subsistiría la naturaleza presentada en el tercer día. Day (2013) comenta que "El primer día de la creación vio lo que es generalmente referido como la creación de la luz, siendo esta la fuente de vitalidad para lo viviente establecido en los otros días" (p. 10). Durante el segundo día, la separación de las aguas fue concluyente para generar la atmósfera, la cual provee compuestos químicos necesarios para procesos biológicos de vital importancia. La luz del día primero y el agua (su separación) del día segundo fueron trascendentales para la aparición del mundo vegetal. En el tercer día, según Nee (2009) llega la vida en materia de plantas y árboles que dan fruto, allí la vida "es incorporada a través de la vegetación primigenia” (p. 100). De este modo, la consistencia del tercer día es epicentro en la cosmogonía del Génesis, pues presenta firmemente tal postulación como el comienzo de la vida.

Keil y Delitzsch (2008) afirma que "la reunión de las aguas y la aparición de la tierra, ya sea por el hundimiento o la profundización de lugares en el cuerpo del globo o los cuales el agua fue circunscrita, o por la elevación de la tierra sólida, ya que este documento nunca describe el proceso" (p. 36), pero en la contemplación directa se puede observar la idea de la articulación de la radiación solar del primer día con la separación y orden acuático del segundo día. Está claro, para Keil y Delitzsch (2008) que desde la perspectiva bíblica "las plantas no fueron producto de los poderes de la naturaleza, generación equivoca en el sentido ordinario de la palabra, sino una obra de divina omnipotencia, por lo cual los árboles llegaron a la existencia antes que sus semillas, y su fruto creado en la plenitud de su desarrollo, sin expandirse gradualmente bajo la influencia de la luz solar y la lluvia" (p. 36). 
Además, Westermann (2004) amplía lo anterior diciendo que "la creación de los seres vivientes inicia con vegetación. Al mismo tiempo en la creación de las plantas se involucran diferentes historias; aquí se comprende la vegetación como una totalidad, y parte de la creación del mundo. Cuando Dios ordena la tierra para traer las plantas, escuchamos la conmoción del mundo" (p. 10). De este modo, se puede notar la organización y secuencia lógica que plantea el relato del Génesis.

Otro tópico de suma importancia, es la clasificación del mundo vegetal, como שא "césped,"

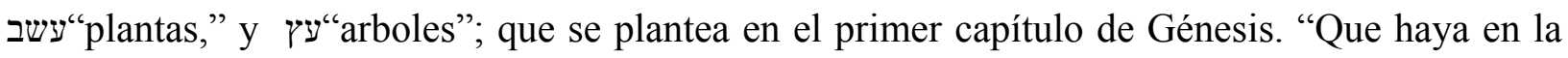
tierra árboles y plantas que den fruto y semilla”. Luego, Delizsch (2001) afirma que Dios creó la creación del ambiente propicio, un terreno fijo y fértil, Dios creó las plantas las cuales estaban sujetas a la disposición de tal expansión. Con la creación de las plantas y árboles se crea la sustentación del hombre y los animales" (p. 81). Para la conformación de un ecosistema integral el suelo desnudo se cubrió de vegetación, y es de notarse que los árboles, las plantas y las hierbastres divisiones del reino vegetal, aquí mencionadas - no fueron llamados a la existencia de la misma manera que la luz y el aire; Jamieson (1956) afirma que "se les hizo crecer, y crecieron, así como todavía crecen de entre la tierra - pero no por el lento proceso de la evolución, sino por poder divino, sin lluvia, ni rocío, ni proceso alguno de trabajo - brotando y floreciendo en un solo día" (p. 17).

Luego entonces es plausibles denotar una relación entre שע עץ ע" שב "céspedantas," “arboles." Aunque a primera vista, esta terminología sugiere tres distintos tipos de vegetación, y esta es la forma en la que generalmente se entienden estos términos. Sin embargo, aunque שא * usualmente solo significa césped, aquí parece ser un amplio término que incluye ambos "plantas" y "arboles." En favor de la interpretación posterior, ambos "plantas" y "arboles" son calificados como auto-propagadores, "semilla-contenida" "contienen frutos", mientras שא no tiene esta calificación. Plantas y árboles son mencionados en los versículos 29-30, pero no el césped (Watts, 1995, p. 15).

Existe un vocablo encargado de describir una variabilidad en el mundo vegetal, probablemente sea demasiado restrictivo insistir que la palabra "tipo" en hebreo es limite a "especie". La palabra hebrea "נימ" (min) según Hamilton (1990) es lo suficientemente amplia como para significar "especie", así como "género, familia y orden. Así pues "min” es abarcante como 
para figurar la variedad del mundo animado.

En busca del concepto bíblico de vida, el término Nephesh es el encargado de trasmitir la aparición de esta en el relato de la creación. Este vocablo hebreo aparece 755 veces en el Antiguo Testamento. Una aproximación segura al definir tal palabra se puede notar cuando se traduce como vida. Con el pasar de los años en la traducción griega del Antiguo Testamento (septuaginta) según Sanchez (2013) se le dio un significado no tan amplio como en el lenguaje original, puesto que se la tradujo como "psiquis" del griego "psujé" cuyo significado se simplifica a "mente" siendo esta solo una parte de lo que el hebreo quería decir con la palabra Nephesh. La palabra hebrea anterior es calificada según Marter (1964) por la palabra hayyih que también significa vida, que en el concepto básico hebreo era toda manifestación del regalo llamado vida que bien podría ser físicos, mentales, morales y emocionales, todo ello como la manifestación de la vida.

Sabiendo que Nephesh es un término utilizado esencialmente para referirse a la vida en su totalidad (Gen. 2:7). Ernst y Claus (1997) en el léxico del Antiguo Testamento agregan que se utiliza al término en cuestión como "salvar vida", o en "conservación de la vida" en génesis 19:17 y Deuteronomio 4:9 respectivamente. Pero debemos tener en claro que el concepto de "vida" de los antiguos semitas no es proporcional al pensamiento moderno; para Samuel (2007) ellos consideraban que "Nephesh sirve como el fundamento de otro (humano), dimensión superior de alma, que no puede existir como todo un ser humano sin la presencia del Nephesh".

Watts (1995) afirma que "las plantas particularmente son un producto de la obra de Dios en el tercer día cada una, שעב "עש "césped,"plantas," y עץ"arboles". Sin embargo, el significado antropológico de Nephesh expuesto por Von Rad (1993) como "lo que vive" y mora en la carne distinguiéndose claramente de ella (Isa. 10:18), genera dificultades en el posicionamiento del origen de la vida en el tercer día. Ya que los animales vendrían a poseer Nephesh, mientras las plantas no. Empero el significado primitivo de Nephesh expuesto en algunos pasajes como “garganta, fauces" (Isa. 5:14) generaría la posibilidad de pensar que simplemente las plantas no tenían un sistema respiratorio compuesto por una garganta y otros conductos biológicos como lo tenían los otros seres vivos.

Finalmente, el modelo bíblico para el origen de la vida es ciertamente una explicación alternativa, digna de consideración puesto que aporta una posible respuesta al enigma del origen 
de la vida.

\section{Conclusiones}

La teoría del mundo del RNA comporta limitaciones de envergadura en su explicación abiogénica del origen de la vida, debido a la falta de evidencias concluyentes respecto a las diferentes transiciones moleculares que dieron lugar al RNA, e incluso la ausencia de una justificación experimental clara para la aparición de vida celular posterior.

Por otro lado, la panspermia no soluciona el problema del origen de la vida, simplemente lo deslocaliza, indagando posibles fuentes extraterrestres que debido a sus condiciones generan una solución contingente al problema. No obstante, las limitaciones encontradas en la literatura reportan la carencia de evidencia inequívoca en el registro fósil y la inminente propensión a la contaminación de los meteoritos arribados a la corteza terrestre.

El origen de la vida es un tema de irresolución científica debido a la carencia de evidencias puntuales que puedan explicar el mecanismo específico para dicho surgimiento. Además, el sistema científico no ha llegado a un consenso para este problema debido a que el objeto de estudio es muy complejo para ser estudiado mediante un método experimental.

Finalmente, el relato bíblico del Génesis tiene particularidades que permiten caracterizarlo

como un relato independiente a las mitologías circundantes del antiguo cercano oriente. Éste tiene un orden lógico de acontecimientos que intenta explicar el surgimiento de la vida en un período corto de tiempo, en el cual la intervención divina crea la vida de forma instantánea. Empero, este registro protológico no pretende explicar detalles de interés científico, sino relatar de manera concisa los acontecimientos que ocurrieron. 


\section{Referencias}

Achtemeier, P., y Rice, E. (1994) The Old Testament Roots of Our Faith. New York: Abingdon Press.

Ahad, M. (2011). (Garcia, 2010) (Gamboa, 2012)Evolution of First Life without Oparin (Primordial Soup) Theory of Evolution: A Critical Review. International Journal of BioResource \& Stress Management.

Anders, E. (1989). Prebiotic organic matter form comets and asteroids. .Nature 342: 255-257.

Armen, Y, Mulkidjanian, A. Cherepanov, M., y. Galperin, Y. (2003). Survival of the Fittest Before the Beginning of Life: Selection of the First Oligonucleotide-Like Polymers by UV Light. Evolutionary Biology.

Bánfalvi, G. (2010) Apoptotic Chromatin Changes. Institute if Biology and Ecology. Springer Press.

Barton, N. (2007). Evolution. New York, Cold Spring Harbor Laboratory Press.

Bedau, M. (2005). The Nature of Life: First. New York: Cambridge University Press.

Bedau, M. (2010). The Nature of Life. Classical and Contemporary Perspectives from Philosophy (Cambridge: Cambridge University Press.

Berenguer, R. (1996). Evolución y creación: entre la ciencia y la creencia (Barcelona: Editorial Ariel S.A.

Bergant, D. (2000). The Collegeville Bible Commentary Based on the New American Bible: Old Testament. Collegeville, MN: The Liturgical Press.

Berkhof, L. (1988). Teología sistemática. Grand Rapids, MI: T.E.L.L.

Bill, A. (2009). Genesis. New York: Cambridge University Press.

Bohidar, H. B. (2008). A Novel State of Soft Matter an Overview. Indian Society for Surface Science and Technology.

Bultmann, R. (1961). Kerygma and Myth. New York: Harper \& Row.

Campbell, D. (2004) Theological Wordbook. Nashville, TN: Word Publishing.

Carrapico, F., y Rodrígues, T. (2005). Symbiogenesis and the Early Evolution of Life. Astrobiology and Planetary Missions.

Clay, A. (2003). Atrahasis: An Ancient Hebrew Deluge Story and Other Flood Story Fragments.

San Diego, CA: Book Tree. 
Couprie, D. (2003). Anaximander in Context: New Studies in the Origins of the Greek Philosophy. New York: State University of New York Press.

Curtis, H. (2008). Biología, 7ma ed. Madrid: Editorial Medica Panamericana, 2008), 15.

Day, J. (2013). From Creation to Babel: Studies in Genesis 1-11. New York: Bloomsburry Academic.

Delitzsch, F. (2001). New Commentary on Genesis. West Broadway, OR: Stock Publishers.

Di Giulio, M. (2010). Biological Evidence Agains the Panspermia Theory. Journal of Theoretical Biology.

Dundes, A. (1988). The Flood Myth. Berkeley, LA: University of California Press.

Dworkin, J., Lazcano, A., y Miller, S. (2003). The Roads to and from the RNA World. Journal of Theorical Biology.

Marter, E. (1964). The Hebrew Concept of "soul" in Pre-exilic Writings. SomersetWest, Cape, South Africa: Helderberg College.

Engel, M y Macko, S. (2001). The stereochemistry of amino acids in the Murchison Meteorite. Precambrian Research. Elsevier Science.

Ernst, J., y Westermann, C. (1997). Theological Lexicon of the Old Testament. Peabody, MA: Hendrickson Publishers.

Flugel, R. (2011). Chirality and Life: A Short Introdution to the Early Phases of Chemical Evolution. New York: Springer.

Freeman, S. (2001). Evolutionary Analisis. Prentice Hall.

Futuyma, D. (2005). Evolution. Massachusetts: Sinauer Associates.

Gargaud, M, Amils, R., y Cleaves, H. (2011). Encyclopedia of Astrobiology. New York: Campbell, N. Biology. New York: Pearson.

Gentry, K. (2016). As It Is Written: The Genesis Account, Literal or Literary? Dismantling the Framework Hypothesis. Green Forest, AR: Master Books.

Gilbert, W., y Souza, S. (1999). Introns and the RNA World. The RNA World. Cold Springer Habor Laboratory Press.

Gowan, D. E. (1988). From Eden to Babel: A Commentary on the Book of Genesis 1-11. International Theological Commentary. Grand Rapids, MI: Eerdmans.

Groseclose, W. (2015) Living Bleesedly Forever: A Systematic Theology Primer. Oxford: Oxford University Press. 
Hamilton, V. (1990). The Book of Genesis 1-17. Grand rapids, MI: Eerdmans.

Hasel, G. (2015). Geoscience Research. Recuperado de http://grisda.net/subEs/wpcontent/uploads/

Hays, L. (2015). Astrobiology Strategy. National Aeronautics and Space Administration. Washington, DC: NASA.

Higgs, P., y Lehman, N. (2014). The RNA World: Molecular Cooperation at the Origins of Life. Nature Reviews Genetics.

Horneck, G., y Rettberg, P. (2007). Complete course in Astrobiology. New York: Wiley.

Horowitz, W. (1998). Mesopotamian Cosmic Geography. Winoma Lake, ID: Eisenbrauns.

Howard, F. (1990). Génesis. Grand Rapids, MI: Portavoz.

Hoyle, F., y Wickramasinghe, C. Astronomical Origins of Life: Steps Towards Panspermia. Dordrecht: Kluwer Academic Publishers.

Hush, E. (2004) Evidence for the Bible. New York: Energion Publications.

Jacobsen T. The Treasures of Darkness.

Jamieson, R., y Brown, D. (1956). Comentario exegético y explicativo de la Biblia: El Antiguo Testamento. Buenos Aires: Casa Bautista de Publicaciones.

Johnston, W., y Unrau, P (2001). RNA-Catalyzed RNA Polymerization: Accurate and General $R N A$ Templated Primer Extension. Science.

Joyce, G. (1996). Ribozymes: Building the RNA World. Current Biology.

Keil y Delitzsch. (2008). Comentario al texto hebreo del Antiguo Testamento. Barcelona: Editorial Clie.

King, L. (2005). Enuma Elish: The Epic of Creation. Grand Rapids, MI: BrazosPress.

Kirschvink, J., y Weiss, B (2001). Mars, Panspermia, and the Origin of Life: Where Did It All Begin? Palaeontologia.

Lazcano, A. (1966). Chemical Evolution and the Primitive Soup. Journal of Theoretical Biology, no. 184.

Lazcano, A, y Wong, T. (2009). Prebiotic evolution and Astrobiology. Austin, TX: Landes Bioscience.

Lepock, S., y Wesson, P. (1994). Damage due to Ultraviolet and Ionizing Radiation during the Ejection of Shielded Micro-organisms from the Vicinity of 1 M Main Sequence and Red Giant Stars-Astrophysics and Space Science. 
MacKenzie, L. (2004) Biology a Search for Order in Complexity. Grand Rapids, MI: Christian Liberty Press.

Martin, L., y Müller, U. (2015). RNA Synthesis by in Vitro Selected Ribozymes for Recreating an $R N A$ World. Niles Lehman: Life.

Martins, Z. (2008). Extraterrestrial Nucleobases in the Murchison Meteorite. Earth and planetary science Letters.

Maxwell, K. (1994). The Sex Imperative: An Evolutionary Tale of Sexual Survival.

Millard, E. (2008). Teología sistemática. Barcelona: Editorial Clie.

Miller, S., y Robertson, M. (1995). An Efficient Prebiotic Synthesis of Cytosine and Uracil. Nature.

Nee, W. (2009).The Mystery of Creation. New York: Christian Fellowship Publishers.

Oparin, A. (1953). The Origin of Life. New York: Dover Phoenix Edition.

Oró, J. (1961). Mechanism of Syntesis of Adenine from Hydrogen Cyanide under Plausible Primitive Earth Conditions. Nature 191.

Persaud, C. (2007). Evolotion: Beyond the Realm of Real Science. New York: Xulon Press.

Pizzarello, S. (2009).The Cosmochemical Record of Carbonaceous Meteorites: An Evolutionary Story. Journal of Mexican Chemical Society.

Pratte, D. Commentary on the Book of Genesis Bible Study Notes and Comments.

Rad, G. (1982). El libro del Génesis. Salamanca: Sígueme.

Rad, G. (1982). El libro del Génesis. Salamanca: Sígueme.

Rad, G. (1993). Teología del Nuevo Testamento. God's image in man and its defacement in the light of modern Denials. London: Hodder and Stoughton.

Rauchfuss, H. (2008). Chemical Evolution and Origin of Life. Berlin: Springer.

Raulin, F. (2007). Organic Chemistry and Exobiology on Titan. Netherlands: Kluwer Academic Publishers.

Ribas, L. (2016). The Genetic Code and the Origin of Life. Landes: Kluwer Academic Plenium Publishers.

Rice University (2003). Concepts of Biology. Austin, TX: Open Stax College.

Rizzotti, M. (1995). A Putative Living Fossil of the Rna World Is Likely to Be of Recent Origin. Chemical Evolution: Physics of the Origin and Evolution of Life. Kluwer Academic 
Publishers.

Rojas, I. (2004). El origen de la vida sobre la tierra. Valparaíso: Pontificia Universidad Católica de Chile.

Samuel, G. (2007). The Kabbalah Handbook. New York: Penguin.

Sánchez, P. (2013). Reflexiones teológicas: Algunos dilemas. Bloomington, IN: Bloomington Press.

Schopf, W. (2010). Life's Origin: The Beginnings of Biological Evolution. California: University of California Press.

Schweitzer, W. The eight elements of the Westminister Doctrine of creation: Why they are incompatible with theistic evolution.

Sgreccia, E. (2008).Teología de la Vida, Vida y ética.

Shaw, A. (2006). Astrochemistry: From Astronomy to Astrobiology. Londres: John Wiley \& Sons.

Silver, B. (1998).The Ascent of Science. New York: Library of Congress.

Solomon, E. (2005). Biology. New York: Thomson Learning.

Staats, G. (2012). A Brief Survey Through the Hebrew Scriptures.

Stojanovic, D. (2008). Link Between Earth and Astrobiologye. Extremophiles.

Sweeney, E. (2008). The Genesis of Israel and Egypt. New York: Algora Publishing.

Szostak, J, Bartel, D y Luisi, P. (2001). Synthesizing life. Nature.

Szweykowska, Z. (2014). The Old and New RNA World. Polish Botanical Society.

Thomas, P y Chyba, C. (1997). Comets and the Origin and Evolution of Life. (New York: Springer.

Traut, T. (2011). Allosteric Regulatory Enzymes (University of North Carolina.

Van Loon, A. J. (2005). The needless search for extraterrestrial fossils on Earth. Science Reviews.

Walton, J. (2004). Ancient Israelite Literature in its Cultural Context. Grand Rapids, MI: Zondervan Publishing House.

Watts, J. (1995). Word Biblical Commentary: Genesis, vol. Dallas, TX: Word Books.

Wenham, G. (1987). Word Biblical Commentary: Genesis 1-15.

Westermann, C. (2004).Genesis. New York: T \& T Clark International. 
Wickramasinghe, C. (2009). Life from Space. Astrobiology and Panspermia. The biochemical Society.

Woolfson, A. (2015). An Improbable Journey. Nature.

Yamaguchi, A. (2012). Antartic meteorites and the origin of planetesimals and protoplanets. Astrophysics from Antarctica. Proceedings IAU Symposium No. 288.

Zaikowski, L., y Friedrich, J. (2008). Chemical Evolution Across Space \& Time: From the Big Bang to Prebiotic Chemistry. American Chemical Society. Washington DC: Oxford University Press. 